\title{
COMPARAÇÃO ENERGÉTICA ENTRE OS PROCESSOS DE OBTENÇÃO DE AROMÁTICOS DE MISTURAS DE HIDROCARBONETOS RICAS EM AROMÁTICOS
}

\author{
A. G. ZACARELLI ${ }^{1}$, C. A. S. FARIA ${ }^{1}$, J. A. MATOS ${ }^{1}$, K. N. ZURI ${ }^{1}$, L. S. O. HAYASIDA ${ }^{1}$, \\ N. L. FERREIRA ${ }^{1, *}$ \\ ${ }^{1}$ Centro Universitário da FEI, Departamento de Engenharia Química \\ *E-mail: nlibanio@fei.edu.br
}

\begin{abstract}
RESUMO: Este trabalho visa comparar energeticamente duas vias de obtenção da fração de hidrocarbonetos aromáticos presentes em uma corrente de hidrocarbonetos: destilação extrativa e extração líquido-líquido. Para a análise energética escolheu-se como matéria básica uma corrente de aromáticos, característica da indústria petroquímica, o reformado. Esta corrente é composta basicamente por benzeno, tolueno e xileno (BTX). Para tanto é necessário confeccionar modelos dos processos comerciais, contendo operações unitárias e o método termodinâmico. Para a simulação foi utilizado o software ASPEN PLUS ${ }^{\circledR}$, por meio do qual escolheu-se a N-metil-2-pirrolidona como o melhor solvente para os dois processos. Através das simulações, para o caso base de extração líquido-líquido, determinou-se um extrator de 12 estágios com seletividade da corrente de extrato e porcentagem de extração de aromáticos igual $83,83 \%$ e 94,25\%, respectivamente. Cada corrente gerada pelo extrator, rafinado e extrato, foram encaminhas para uma coluna de destilação fracionada. Dessa forma, para a coluna de destilação do extrato foi obtida uma seletividade da corrente de BTX de 90,08\% e porcentagem de extração de aromáticos de $86,33 \%$. Já para a coluna de destilação do rafinado foi obtida uma seletividade da corrente de não aromáticos de 98,44\% e porcentagem de extração de não aromáticos de 94,38\%. A fim de otimizar cada processo, fez-se uma integração energética adicionando trocadores de calor, e com isso foi possível obter um consumo específico de 485,61 kcal/kg de BTX e uma massa de água de resfriamento de $70 \mathrm{~m}^{3} / \mathrm{h}$. Para o caso base de destilação extrativa foi obtido 95,29\% e 90,21\% de porcentagem de extração de aromáticos e seletividade, respectivamente, para uma coluna de 10 estágios teóricos. A corrente de extrato seguiu para uma coluna de destilação fracionada, onde se obteve uma seletividade de 90,23\%, e porcentagem de extração de aromáticos de 93,05\%. A corrente de rafinado também passou por uma coluna de destilação fracionada, onde obtiveram-se como resultados $95,73 \%$ de porcentagem de extração de não aromáticos e $85,81 \%$ de seletividade. Adicionado os trocadores de calor obteve-se um consumo específico de 430,82 kcal/kg de BTX e uma vazão de água de resfriamento de $102 \mathrm{~m}^{3} / \mathrm{h}$.
\end{abstract}

PALAVRAS-CHAVE: destilação; extração; aromáticos; BTX. 


\section{INTRODUÇÃO}

O petróleo é composto, principalmente, por moléculas formadas por átomos de carbono e hidrogênio. Essas moléculas se combinam, de tal modo que o óleo ganha algumas características, e assim se torna possível classificá-lo em: parafínico, naftênico, aromático ou misto (CEFET, 2015).

Segundo Franchi e Listik (2014), uma das frações mais importantes do petróleo é a nafta, que após sofrer o processo de reforma catalítica produz a chamada nafta reformada. Este processo consiste em transformar as substâncias n-parafínicas e naftênicos em aromáticos por meio de reações como desidrogenação, desidrociclização, hidrocraqueamento e isomerização. Dessa forma, a corrente gerada apresenta em sua composição elevada quantidade de benzeno, tolueno e xileno, mistura denominada de BTX. Esta é separada da corrente da nafta através do uso de solventes seletivos como o sulfolano, etilenoglicol, Nmetil-2-pirrolidona e outros (RODRIGUES, 2014). O processo de obtenção do BTX pode ser observado na Figura 1.

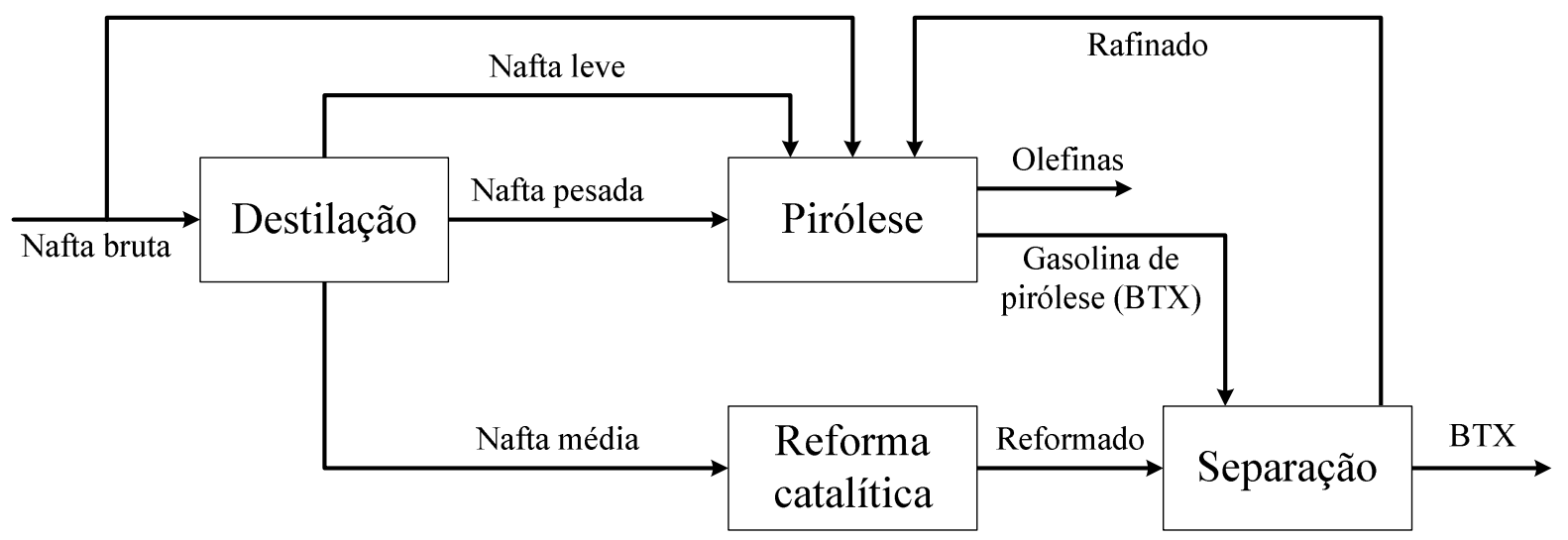

Figura 1 - Fluxograma do processo de obtenção de BTX.

Segundo Leal, Tiburtius e Zamora (2004), a importância da separação do BTX está ligada ao fato que, ao longo das últimas décadas, a preservação das águas, superficial e subterrânea, tem se tornado uma preocupação mundial, devido ao aumento populacional e das atividades industriais. Um dos maiores contaminadores gerados são os compostos orgânicos, no qual se destaca a mistura BTX, que representam sérios problemas à saúde, uma vez que são mais tóxicos e apresentam maior solubilidade em água que os compostos alifáticos.

Desta forma, sabendo que o descarte inadequado de BTX pode provocar danos ambientais e a saúde humana, a separação de seus compostos para posterior uso dos mesmos como matéria prima de muitos processos industriais torna-se uma solução para este problema. Sendo assim, é proposto neste trabalho estudar a comparação energética entre dois processos de separação do BTX da corrente de nafta, sendo eles destilação extrativa e extração líquido-líquido. 


\section{METODOLOGIA}

\subsection{Determinação do Modelo Termodinâmico e do Solvente}

A escolha do modelo termodinâmico, entre NRTL, UNIFAC e UNIQUAC, para o processo estudado está atrelada às características da mistura, que pode ser dividida em duas frações, aromáticos e alifáticos, que desviam do comportamento ideal pela formação de azeótropos e equilíbrio líquido-líquido. Dessa forma, o modelo termodinâmico deve prever o cálculo da fugacidade utilizando o coeficiente de atividade.

Os solventes dióxido de enxofre, dietilenoglicol, sulfolano, N-metil-2-pirrolidona (NMP), dimetilsulfóxido e $\mathrm{N}$-formilmofolina já foram utilizados neste tipo de separação. $\mathrm{O}$ solvente NMP é usado em vários processos comerciais como o AROSOLVAN® e DISTAPEX®. Realizou-se um estudo no software ASPEN PLUS®, no qual foram inseridos todos os componentes do processo juntamente com os solventes a serem estudados e a partir desses dados foram efetuados diagramas binários, selecionando-se um componente e um solvente.

\subsection{Estudo dos Casos}

Obtenção de BTX a partir do processo de extração líquido-líquido: As operações unitárias para o processo de extração líquido-líquido foram definidas com base no processo AROSOLVAN: extrator, coluna de destilação fracionada e trocador de calor (FOLKINS, 2011).

Com a definição das operações unitárias, iniciou-se o estudo do caso base do processo, que consiste no estudo da principal operação unitária, no caso o extrator. Dessa forma, para definir a melhor condição de operação do extrator para a separação dos aromáticos foi necessário seguir algumas etapas apresentadas na Figura 2.

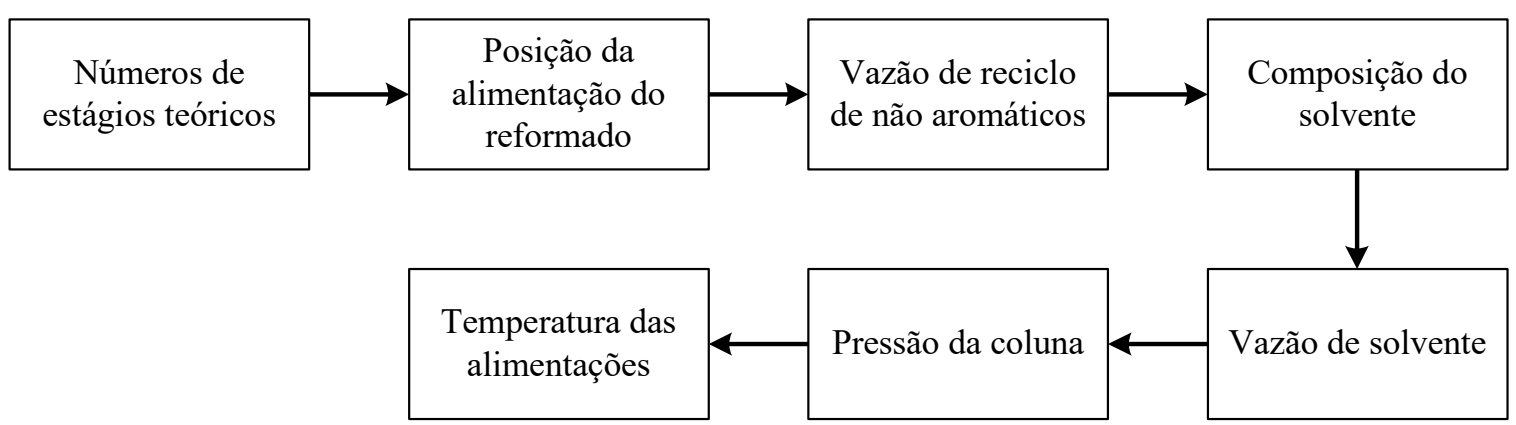

Figura 2 - Fluxograma para a construção do caso base para o extrator.

Após a corrente de reformado passar pela extratora são geradas duas correntes, extrato e reformado, sendo o extrato a corrente de fundo e composta majoritariamente por aromáticos e solvente e o rafinado a corrente de topo composta por não aromáticos e uma fração de solvente.

Para a obtenção dos aromáticos, não aromáticos e a recuperação de solvente, as correntes geradas no processo necessitaram ser separadas, e dessa maneira, foram alimentadas a uma coluna de destilação fracionada. 
Para a construção da coluna de destilação fracionado do extrato e para a coluna de destilação fracionado do rafinado foram seguidos alguns passos que podem ser observados nas Figura 3.

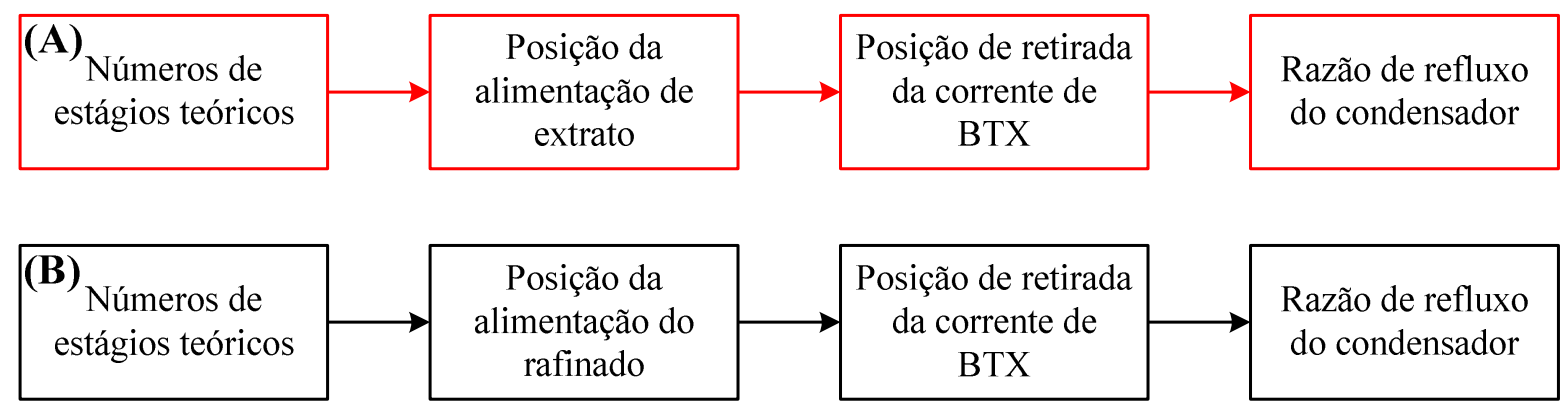

Figura 3 - Fluxograma da construção da coluna de destilação: A) fracionado do extrato e B) fracionado do rafinado

Após determinar as melhores condições de operação do processo, realizou-se uma análise energética que consiste na realização de uma integração energética no processo, por meio da inserção de trocadores de calor, para haver uma economia em utilidades (vapor). Além disso, fez-se duas estruturas de reciclo a fim de otimizar o processo. Os trocadores de calor podem ser observados na Figura 4 e suas funções na Tabela 1.

Tabela 1 - Trocadores de calor implementados no processo de extração líquido-liquido.

\begin{tabular}{cc}
\hline Trocadores de calor & Características \\
\hline TROC-01 & Pré aquecer a corrente de rafinado \\
TROC-02 & Pré aquecer a corrente de extrato \\
TROC-03 & Resfriar a corrente de BTX até $45^{\circ} \mathrm{C}$ \\
TROC-04 & Resfriar a corrente de reciclo até $50{ }^{\circ} \mathrm{C}$ \\
\hline
\end{tabular}

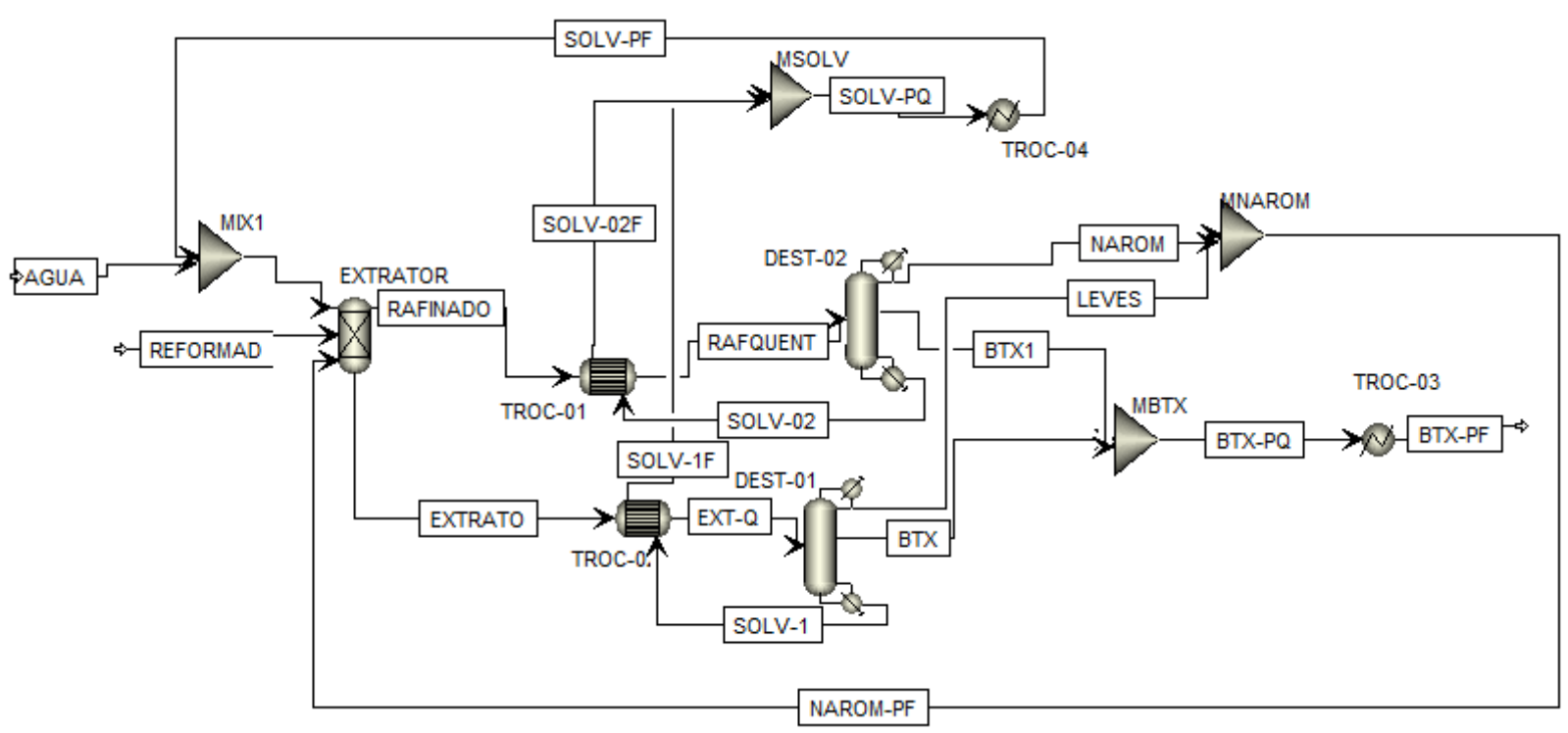

Figura 4 - Fluxograma do processo de extração líquido-líquido. 
Obtenção de BTX a partir do processo de destilação extrativa: A escolha das operações unitárias para o processo de destilação extrativa baseia-se no processo DISTAPEX, onde são empregados uma coluna de destilação extrativa, coluna de destilação fracionada e trocadores de calor.

Para a construção do modelo de destilação extrativa, foi necessário seguir algumas etapas: construção do caso base para a coluna de destilação extrativa e construção das colunas de destilação fracionadas para o extrato e rafinado. A construção do modelo pode ser observada nas Figura 5.

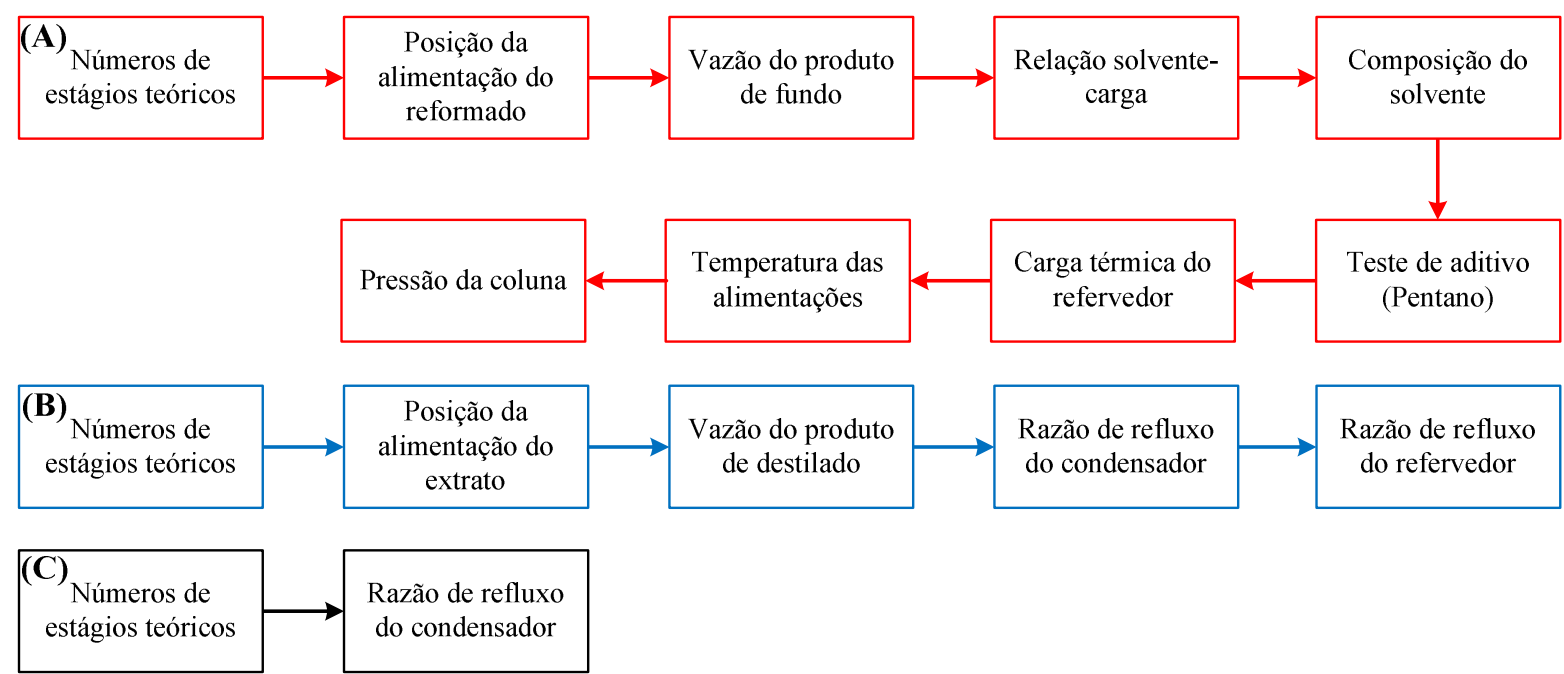

Figura 5 - Fluxograma para construção: A) do caso base para a destilação extrativa; B) da coluna de destilação fracionada do extrato e C) da coluna de destilação fracionada do rafinado.

Assim como no processo de extração líquido-líquido, foi implementado trocadores de calor para a análise energética do processo de destilação extrativa e o reciclo de solvente para otimizar o processo. Os trocadores de calor implementados no processo podem ser observados na Figura 6 e suas características na Tabela 2.

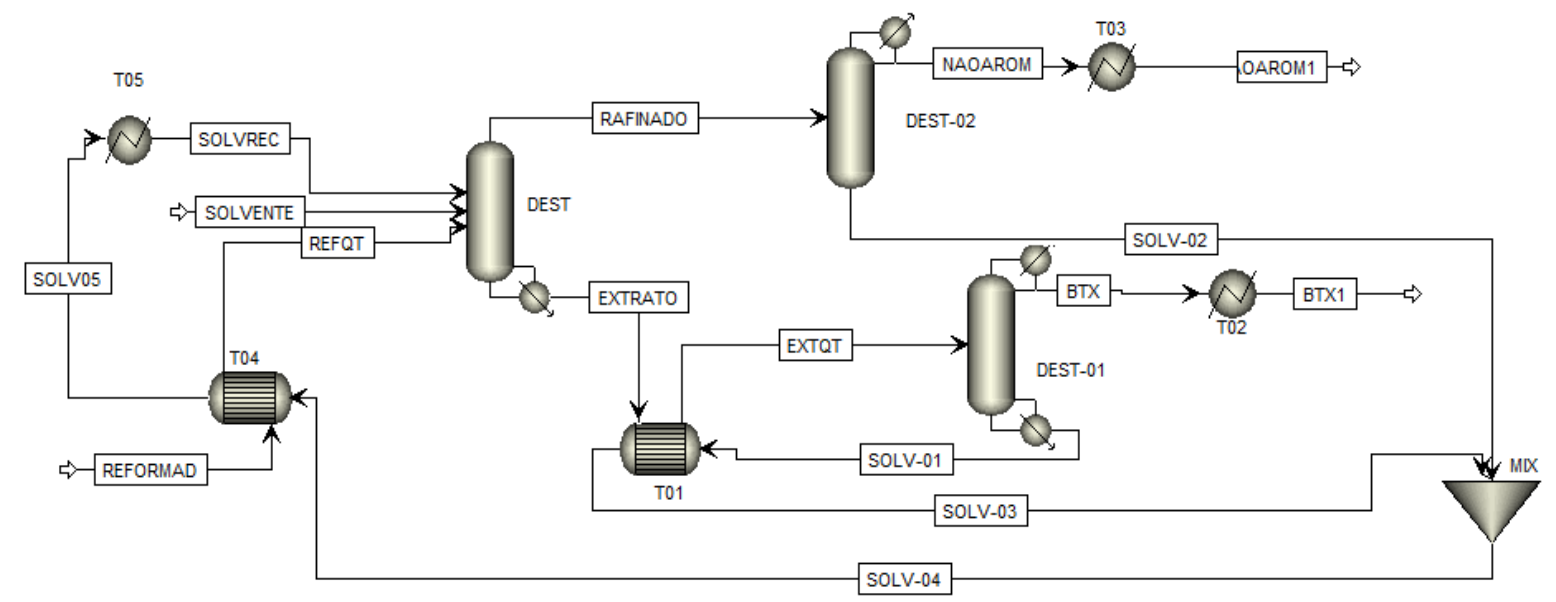

Figura 6 - Fluxograma do processo de destilação extrativa. 
Tabela 2 - Trocadores de calor implementados no processo de extração líquido-liquido.

\begin{tabular}{cc}
\hline Trocadores de calor & Características \\
\hline T01 & Pré aquecer a corrente de extrato \\
T02 & Resfriar a corrente de BTX até $45^{\circ} \mathrm{C}$ \\
T03 & Resfriar a corrente de não aromáticos até $45^{\circ} \mathrm{C}$ \\
T04 & Aquecer a corrente de reformado até $50{ }^{\circ} \mathrm{C}$ \\
T05 & Resfriar a corrente de reciclo de solvente até $55^{\circ} \mathrm{C}$ \\
\hline
\end{tabular}

\section{RESULTADOS E DISCUSSÃO}

Para os processos de destilação extrativa e extração líquido-líquido foram obtidos uma porcentagem de extração de aromáticos referente ao processo como um todo de $94 \%$ e $93 \%$, respectivamente. A corrente de aromáticos obtida no processo de destilação extrativa é composta em $85 \%$ da mistura BTX enquanto no processo de extração líquido-líquido a corrente de produto é composta em $82 \%$ de BTX. Os resultados comparativos entre as características de operação dos processos e os resultados da comparação energética são mostrados nas Tabela 3 e 4 , respectivamente.

Tabela 3 - Comparação entre as características de operação dos processos de obtenção de BTX.

\begin{tabular}{|c|c|c|c|c|}
\hline \multirow{2}{*}{$\begin{array}{l}\text { Características } \\
\text { Número de estágios (-) }\end{array}$} & \multicolumn{2}{|c|}{ Coluna extratora } & \multicolumn{2}{|c|}{$\begin{array}{r}\text { Coluna de destilação } \\
\text { extrativa }\end{array}$} \\
\hline & & 12 & & 10 \\
\hline Estágio de alimentação do reformado (一) & & 10 & & 4 \\
\hline Vazão da corrente de reciclo $(\mathrm{kg} / \mathrm{h})$ & & 1500,00 & & Sem reciclo \\
\hline Razão de reciclo de reformado $\left(\mathrm{kg}_{\mathrm{rec}} / \mathrm{kg}_{\mathrm{ref}}\right)$ & & 0,30 & & Sem reciclo \\
\hline Água na corrente de solvente (\%) & & 2,00 & & 0,00 \\
\hline Vazão da corrente de solvente $(\mathrm{kg} / \mathrm{h})$ & & 5750,00 & & 6000,00 \\
\hline Razão do solvente reformado $\left(\mathrm{kg}_{\mathrm{sol}} / \mathrm{kg}_{\mathrm{ref}}\right)$ & & 1,15 & & 1,20 \\
\hline Pressão do extrator (bar) & & 2,00 & & 1,05 \\
\hline Temperatura da corrente de reformado $\left({ }^{\circ} \mathrm{C}\right)$ & & 50,00 & & 50,00 \\
\hline Temperatura da corrente de solvente $\left({ }^{\circ} \mathrm{C}\right)$ & & 50,00 & & 55,00 \\
\hline Calor do refervedor $(\mathrm{kcal} / \mathrm{h})$ & & Sem refervedor & & 0,50 \\
\hline Extração de aromáticos (\%) & & 97,67 & & 95,38 \\
\hline Seletividade da corrente de extrato (\%) & & 82,54 & & 90,03 \\
\hline \multirow{2}{*}{ Características } & \multicolumn{2}{|c|}{ Extração líquido-líquido } & \multicolumn{2}{|c|}{ Destilação extrativa } \\
\hline & OP1 & OP2 & OP1 & OP2 \\
\hline Número de estágios (-) & 20 & 20 & 10 & 9 \\
\hline Estágio da alimentação de estrato (-) & 16 & 18 & 9 & 9 \\
\hline Estagio de retirada de BTX $(-)$ & 5 & 5 & Sem retirada & Sem retirada \\
\hline Razão de refluxo do condensador ( $(-)$ & 7,00 & 4,00 & 1,90 & 0,20 \\
\hline Razão de refluxo do refervedor (一) & Sem refervedor & Sem refervedor & 1,4 & Sem refervedor \\
\hline Extração de aromáticos (\%) & 97,00 & 98,48 & 92,76 & 95,19 \\
\hline Seletividade da corrente de extrato (\%) & 96,61 & 97,42 & 89,71 & 87,99 \\
\hline Solvente na corrente de não aromáticos (ppm) & 20,00 & 4,00 & Sem saída & 4,00 \\
\hline Solvente na corrente de BTX (ppm) & 26,00 & 3,00 & 10,00 & Sem saída \\
\hline
\end{tabular}


Tabela 4 - Análise energética dos processos de obtenção de BTX.

\begin{tabular}{lrr}
\hline \multirow{2}{*}{ Consumo } & \multicolumn{2}{c}{ Análise energética } \\
\cline { 2 - 3 } & $\begin{array}{r}\text { Extração } \\
\text { líquido-líquido }\end{array}$ & $\begin{array}{r}\text { Destilação } \\
\text { extrativa }\end{array}$ \\
\hline Específico da corrente de BTX $\left(\mathrm{kcal} / \mathrm{kg}_{\text {produto }}\right)$ & 485,61 & 430,82 \\
Específico da coluna de reformado $\left(\mathrm{kcal} / \mathrm{kg}_{\text {reformado }}\right)$ & 360,81 & 316,84 \\
Água de resfriamento $\left(\mathrm{m}^{3}\right)$ & 69,60 & 102,4 \\
\hline
\end{tabular}

\section{CONCLUSÃO}

O trabalho presente visou comparar energeticamente dois processos de separação de aromáticos, destilação extrativa e extração líquido-líquido. Para o estudo da simulação no software ASPEN PLUS ${ }^{\circledR}$, concluiu-se que o modelo termodinâmico mais adequado para ser utilizado era o NRTL, por possuir maiores quantidades de informações dos compostos, como o desvio da idealidade. Em ambos os processos havia a necessidade da utilização de um solvente que no caso, foi escolhido a N-metil-2-pirrolidona por apresentar mais diagramas binários com os compostos da solução que se desejava separar. Além disso, processos como o DISTAPEX e o AROSOLVAN utilizaram a N-metil-2-pirrolidona como solvente e possuíam dados disponíveis para o auxílio da análise, o que possibilitou a escolha das operações unitárias que compunham o processo. Dessa forma, foi determinado que em ambos os processos as correntes de aromáticos e não aromáticos eram separadas do solvente através da destilação fracionada e que essa corrente de solvente era reciclada para o processo.

Para esta coluna, a saída da corrente de aromáticos, denominada de BTX, acontecia no quinto estágio para garantir uma boa seletividade a corrente e também para aproveitar os compostos leves (não aromáticos) que não foram separados no extrator. A coluna de destilação fracionada da corrente de rafinado também apresentou vinte estágios teóricos, com refervedor e condensador, no entanto a alimentação do rafinado ocorria no décimo oitavo estágio. Nesta coluna, havia uma retirada de aromáticos no quinto estágio, para a recuperação dos aromáticos que foram arrastados no extrator.

Com a finalidade de melhorar o processo e aproveitar os calores contidos nas correntes geradas no processo foi adicionado trocadores de calor em ambos os processos. Dessa forma, o processo de destilação extrativa apresentou como produto uma corrente de aromáticos de $3677,2 \mathrm{~kg} / \mathrm{h}$, sendo $85 \%$ desta massa composta por BTX e uma porcentagem de extração, no processo, de $94 \%$. Já o processo de extração líquido-líquido apresentou um pequeno aumento na quantidade de produto, $3715 \mathrm{~kg} / \mathrm{h}$, mas uma diminuição para $82 \%$ da massa composta por BTX e uma porcentagem de extração, no processo, de $93 \%$.

Para a análise energética dos processos de destilação extrativa e extração líquidolíquido foi comparado três parâmetros, o consumo especifico do reformado $\left(\mathrm{CE}_{\text {reformado }}\right)$, o consumo especifico da corrente de BTX (CEBTX) e a massa de água utilizada nos resfriadores (mágua). O processo de destilação extrativa apresentou como resultados: $\mathrm{CE}_{\text {reformado }}=316,8$ $\mathrm{kcal} / \mathrm{kg}$ da corrente de reformado, $\mathrm{CE}_{\mathrm{BTX}}=485,6 \mathrm{kcal} / \mathrm{kg}$ da corrente de BTX e mágua $=102,4 \mathrm{~m}^{3} / \mathrm{h}$. Já o processo de extração líquido-líquido apresentou como resultados $\mathrm{CE}_{\text {reformado }}=360,8 \mathrm{kcal} / \mathrm{kg}$ da corrente de reformado $\mathrm{CE}_{\mathrm{BTX}}=430,8 \mathrm{kcal} / \mathrm{kg}$ da corrente de $\mathrm{BTX}$ e mágua $=69,6 \mathrm{~m}^{3} / \mathrm{h}$. 
Portanto, pelos resultados obtidos percebe-se que o processo de destilação extrativa apresentou um melhor consumo específico tanto para o reformado quanto para a corrente de BTX, uma vez que necessita de menos energia por produto alimentado ou produzido. No entanto, percebe-se que essa diferença entre os consumos especificos é pequena se comparada a quantidade de água necessária para o resfriamento dos processos, uma vez que a extração líquido-líquido consome muito menos água que processo de destilação extrativa.

Dessa forma, pode-se concluir que entre os processos estudados o que melhor apresentou resultado foi o processo de extração líquido-líquido, pois apresentou menor consumo de água. No entanto, pode-se ressaltar que esses resultados apresentados não são conclusivos para escolha de um dos processos, pois seria necessário avaliar o investimento inicial para cada operação, a complexidade das instalações, o espaço e a quantidade de recurso disponíveis para o processo, assim como a necessidade da implementação de sistemas de controle.

\section{AGRADECIMENTOS}

Ao Centro Universitário FEI pelo suporte para o desenvolvimento do trabalho.

\section{REFERÊNCIAS}

\section{CENTRO FEDERAL DE EDUCAÇÃO TECNOLÓGICA (CEFET). Indústria}

Petroquímica. Disponível em:

<http://www.ifba.edu.br/professores/diogenesgaghis/TQ_Teconologia\%20Qu\%C3\%A

Dmica/TQ-Petroqu\%C3\%ADmica.ppt>. Acesso em: 25 ago. 2015.

FOLKINS, Hillis O. Benzene In: Ullmann's encyclopedia of industrial chemistry. $7^{\text {th }}$ ed. Weinheim: VCH, c2011. v. 5, p. 237-268.

FRANCHI, M. G. S.; LISTIK, E. Design, dimensionamento e análise econômica de um sistema de separação para mistura BTX oriunda da reforma catalítica da nafta. 2014.106 f. TCC (Graduação em Engenharia Química) - Escola politécnica da Universidade de São Paulo, São Paulo. Disponível em: $<$ http://sites.poli.usp.br/p/augusto.neiva/TCC/TCCs-finais-2014/2014-24.pdf >. Acesso em: 25 ago. 2015

LEAL, S.L.;TIBURTIUS, E. R. L.; ZAMORA, P.P. Contaminação de águas por BTXs e processos utilizados na remediação de sítios contaminados. Química Nova, São Paulo, v.27, n.3, p. 441-446, maio/jun 2004. Disponível em: $<$ http://www.scielo.br/scielo.php?script=sci_arttext\&pid=S010040422004000300014\&lng=pt\&nrm=iso\&tlng=pt>. Acesso em: 25 ago. 2015.

RODRIGUES, C.M. Desenvolvimento de modelo matemático do sistema reacional de uma unidade industrial de reforma catalítica de nafta com leito móvel. 2014. $80 \mathrm{f}$. Dissertação de Mestrado (Mestrado em Engenharia Química) - Escola Politécnica da Universidade de São Paulo, São Paulo, 2014. Disponível em: $<$ http://www.teses.usp.br/teses/disponiveis/3/3137/tde-26122014-165542/en.php>. Acesso em 15 mar. 2016. 


\title{
AN ENERGY CONSUMPTION COMPARISON BETWEEN SEPARATION PROCESSES FOR AROMATICS OBTENTION FROM AROMATICS RICH HYDROCARBON MIXTURES
}

\author{
A. G. ZACARELLI ${ }^{1}$, C. A. S. FARIA ${ }^{1}$, J. A. MATOS ${ }^{1}$, K. N. ZURI ${ }^{1}$, L. S. O. HAYASIDA ${ }^{1}$, \\ N. L. FERREIRA ${ }^{1, *}$ \\ ${ }^{1}$ FEI University, Department of Chemical Engineering \\ *E-mail: nlibanio@fei.edu.br
}

\begin{abstract}
This work aims the comparison of energy consumption between two petrochemical routes $i$. e. AROSOLVAN and DISTAPEX. Both are wide used routes for aromatics production form hydrocarbon rich mixtures. As raw material was chosen a reformate mixrure rich in the three major substances namely benzene, toluene, and xylenes. The mixture of these aromatics is the main product and is known as BTX. The solvent is $N$ methyl-2-pirrolidone (NMP). For the analysis both processes were modeled in the software ASPEN PLUS ${ }^{\circledR}$. It was also studied the influence of other solvents. As result for the AROSOLVAN process it was obtained a heat consumption of 485,6 kcal/kg of BTX and 70 $\mathrm{m}^{3} / \mathrm{h}$ of cooling water. For the DISTAPEX process the heat comsumption was $430,8 \mathrm{kcal} / \mathrm{kg}$ ofe BTX and $102 \mathrm{~m}^{3} / \mathrm{h}$ of cooling water. As can be seen both processes are equivalent in the matter of energy consumption.
\end{abstract}

KEYWORDS: distillation; extraction; aromatcis; BTX. 